cannabis use and schizophrenia, were not present. Similar results were obtained in a longitudinal study based on patients treated in Stockholm County (Allebeck et al, 1993).

Thus, although our research did not address the specific issue of "drug induced psychosis", as defined by Poole \& Brabbins, we believe there is evidence that cannabis use may increase the risk of psychosis, in particular schizophrenia, beyond the immediate effect of intoxication or flashback.

Allebeck, P., Adamsson, C., Engström, A., et al (1993) Cannabis and schizophrenia: a longitudinal study of cases treated in Stockholm County. Acta Psychiatrica Scandinavica, 88, 21-24. Andréasson, S., Allebeck, P., Engstróm, A., et al (1987) Cannabis and schizophrenia. A longitudinal study of Swedish conscripts. Lancet, ii, 1483-1486.

-, - \& RYDBERG, U. (1989) Schizophrenia in users and nonusers of cannabis. Acta Psychiatrica Scandinavica, 79, 505-510.

POOLE, R. \& BRABBns, C. (1996) Drug induced psychosis. British Journal of Psychiatry, 168, 135-138.

University of Göteborg

P. Allebeck

Göteborg, Sweden

St Göran Hospital

Stockholm, Sweden

\section{S. ANDREASSON}

\section{Ultra-rapid mood cycling}

SIR: Kramlinger \& Post (1996) intrigued me when they made reference to the potential contribution of prior sexual abuse to ultra-rapid mood cycling. Two further 'ultra-rapid' cases may be of interest. The first is a woman under intensive community based treatment and requiring frequently fine tuned polypharmacy for many years. An attempt to improve her chronically disabled state with a major revision and reduction of treatment was followed by over a year of chaos with mood cycling as often as every three days, depressions lasting many weeks, marked suicidality and apparent gestures of same. In the midst of this, many years into treatment, the patient surprised everyone by disclosing sexual abuse, and subsequently during the brief good spells took up an evening class and used public transport for the first time in a decade. The mood cycles continue but her functioning is undoubtedly improved. The second patient disclosed sexual abuse far earlier in her symptoms, but while her depressions seem typical, her rapid swings into the subjective complaint of 'being high' is vague and at times unconvincing. The striking thing about these two people, apart from the rapidity of their mood swings however is that both cling to a bio- logical cause to their problems. It may well be that this is appropriate insight and a success of treatment, but I am struck that both high and low mood states prevent proper communication and may confer secondary gain. Furthermore might a diagnosis confer a form of personal identity seemingly lacking in survivors of abuse, and the hyperarousal following trauma respond partly to the majority of treatments employed which tend to reduce arousal and awareness?

While not suggesting that treatments should or could be withheld, I welcome Kramlinger \& Post flagging the wider aetiological possibilities of this challenging disorder.

KrAmLInger, K. G. \& Post, R. (1996) Ultra-rapid and ultradian cycling in bipolar affective illness. British Journal of Psychiatry. $168,314-323$.

Wrexham Maelor Hospital

C. S. LiTtLejohiNs Wrexham, Clwyd, North Wales

\section{No right to a Mental Health Review Tribunal?}

SIR: The Mental Health Act (MHA) 1983 allows all detained patients, on sections providing for detention of longer than 72 hours, the right to appeal to a mental health review tribunal (MHRT) against their detention. Or so I believed. I have recently become aware that there are certain individuals who, when admitted to hospital under section 3 of the MHA 1983, are not entitled to a MHRT.

A patient at the Reaside Clinic in Birmingham detained under sections 37 and 41 of the MHA 1983 was granted a conditional discharge by a MHRT. The necessary conditions were met and the patient was discharged into the community. With such a discharge the Home Secretary may recall the patient to hospital at any time. The responsible medical officer (RMO) does not have the power to recall the patient, but can advise the Home Secretary to do so.

The patient's condition subsequently deteriorated in the community necessitating compulsory readmission to hospital under section 3 of the MHA 1983. It was hoped that detention under section 3 would allow greater clinical flexibility than recall by the Home Secretary, as such recall can lead to lengthy negotiations with the Home Office prior to release.

The patient objected to his detention under section 3, and therefore applied to the MHRT but the application was refused. The Department of Health has provided me with a legal opinion which 